\title{
CONTRAPUNTO SOBRE EL ROL DE LA CONTRALORÍA GENERAL DE LA REPÚBLICA
}

\section{OPPOSITES POINT OF VIEWS ABOUT THE CHILEAN'S GENERAL OFFICE COMPTROLLER'S DUTIES}

La Dirección de la Revista Chilena de Derecho invitó a participar en la sección de Ensayos y Crónicas a los profesores de Derecho: Dr. Alejandro Vergara* (en adelante A.V.), de la Pontificia Universidad Católica de Chile y Francisco Zúñiga ${ }^{* *}$ (en adelante F.Z.), de la Universidad Diego Portales, para que respondieran cinco preguntas relativas a un tema de Derecho Administrativo que ha tenido eco en diversas columnas de opinión y foros de debate: el rol de la Contraloría General de la República.

1. En una presentación efectuada en octubre de 2007 por el señor Contralor General de la República, don Ramiro Mendoza, se señaló como uno de los objetivos del plan de modernización institucional de la Contraloría "constituirse en el eje principal del fortalecimiento de la probidad pública y -por ahora- en la promoción de la transparencia de la gestión pública”. ¿Comparte está visión sobre el rol que corresponde a la Contraloría General de la República? ¿Qué aspectos considera usted más demostrativos de ese afán en la labor que ha desarrollado la CGR hasta la fecha? ¿Estima que han cumplido el propósito señalado por el Contralor?

A.V.: El tema central de la pregunta es la probidad y transparencia administrativa en el accionar de la Contraloría. Al respecto, cabe precisar de partida que la CGR es en esencia competente para la fiscalización del debido ingreso e inversión de los fondos públicos, y para realizar el control preventivo de juridicidad de los DS, Resoluciones y otros actos; y, a posteriori, de la actuación de la Administración, mediante fiscalizaciones de sus procedimientos.
Además, debe vigilar el cumplimiento del Estatuto Administrativo. Para ello está dotada de una prestancia institucional necesaria: su autonomía. Sin ella, sería un dependiente del Presidente de la República; cuyo no es el caso.

El eje central de la función que realiza tiene que ver directamente con el control, cumplimiento y efectividad de la juridicidad administrativa. Es la naturaleza de la actividad y competencia de la CGR la que le imponen el cumplimiento de estas reglas y principios, en cuanto fiscalizadores y controladores de dos cuestiones de forma general: la inversión fiscal y la legalidad de los actos administrativos.

Las reglas y principios de probidad y transparencia, que informan la actividad administrativa, están reconocidos constitucional y legalmente; deben informar toda la actividad administrativa, en especial las actividades que por Ley le compete fiscalizar a la CGR.

En fin, probidad y transparencia forman también parte del núcleo o esencia de la juridicidad de la actividad administrativa de la propia CGR. El mismo órgano contralor debe ser el primero en mostrar y demostrar de una manera proba, abierta y transparente su actuación. La CGR debiese ser como un cristal traslúcido para el ciudadano, a través del cual ob-

\footnotetext{
* Licenciado en Derecho Universidad de Concepción, Doctor en Derecho Universidad de Navarra, Profesor de Derecho Administrativo Pontificia Universidad Católica de Chile.

${ }^{* *}$ Licenciado en Derecho Universidad de Chile, Postgrado en Derecho Público y Comparado Universidad Autónoma y Complutense de Madrid y Postgrado en Derecho Constitucional. Centro de Estudios Políticos y Constitucionales de Madrid.
} 
serve íntegra a la propia CGR, y, a partir de ella, pueda observar al resto de la Administración fiscalizada.

Los aspectos más demostrativos de la actualidad tienen que ver con toda la información que puede extraerse del sitio Web de la CGR, en cuanto a la publicación de informes de fiscalizaciones y auditorias, la publicación de todos los dictámenes y demás informaciones que se suben relacionadas con las audiencias, o reuniones del Contralor. ¿Tareas pendientes? Ofrecer toda la información de cada procedimiento en línea (on line), exigiendo que todo documento sea presentado en archivo electrónico.

Avanzar cada vez más desde la opacidad antigua a la traslucidez máxima posible.

F.Z.: La Contraloría General de la República es un organismo de control de la Administración del Estado revestido de un amplio abanico de funciones: control de legalidad de los actos de la Administración, fiscalización del ingreso e inversión de los fondos públicos, examen y juzgamiento de cuentas, contabilidad general de la Nación y demás funciones que le encomiende la ley orgánica constitucional (artículo 98 C.P.R.). Este abanico de funciones nos demuestra elocuentemente la hipertrofia de tareas o cometidos del organismo contralor, que excede a la competencia de organismos homónimos en América. A pesar de tal hipertrofia el organismo contralor, con recursos materiales y humanos limitados, las cumple no sin dificultades.

En consecuencia, se hace necesario abordar una reforma institucional de la Contraloría General de la República, la que es planteada en el valioso proyecto de Reforma Constitucional en materia de Transparencia, Modernización del Estado y Calidad de la Política, en actual trámite en la Cámara de Diputados. El proyecto de Reforma Constitucional fue objeto de un informe expedido por el Contralor General de la República que de algún modo recoge las definiciones estratégicas de la cabeza jerárquica de este organismo contralor (Of. No 56167 de 10 de diciembre de 2007).

En el marco de esta definición estratégica del organismo contralor se sitúa como eje principal el fortalecimiento de la probidad pública. La reorientación que se observa hoy de la labor fiscalizadora del organismo controlador hacia la auditoria es congruente con el referido fortalecimiento de la probidad pública.

\section{La fuerte fiscalización realizada por la} CGR en la actualidad respecto de los servicios públicos y municipalidades ha importado un mayor conocimiento público de falencias en la gestión de estos e incluso irregularidades: ${ }_{\llcorner}$Considera usted que esta situación importa un deterioro de la percepción de la ciudadanía sobre la probidad administrativa en Chile y, en consecuencia, una mayor impresión de corrupción?

\section{A.V.: El impacto de la fiscalización de la} CGR en la ciudadanía, sobre la bases de los principios de publicidad y transparencia, no es un fenómeno que le corresponda a la ciencia del Derecho analizar ni constatar; será objeto, en su caso, de la sociología o de otras ciencias que se encarguen de verificar el impacto social y psicológico que hayan tenido. E, intermediado por la ciencia política, y las políticas públicas, a decisiones legales.

No obstante, desde la perspectiva del Derecho, es posible decir que la sensación de fiscalización pudiera tener efectos en el ámbito del reconocimiento y fortalecimiento de los derechos de los ciudadanos de frente a la gestión pública; que se traduzca en una nueva mirada del rol de las administraciones públicas a las que se les podrá exigir como derechos un actuar más transparente, probo, eficiente y oportuno. También, la fiscalización produce un efecto disuasivo innegable en los burócratas amigos del desorden y de las faltas de probidad.

Pero, en verdad, ha sido la agudeza y oficio del nuevo contralor y la efectividad de estas fiscalizaciones lo que ha provocado un impacto importante en la opinión pública nacional.

F.Z.: La fiscalización de servicios públicos y de municipalidades por la Contraloría General de la República se efectúa principalmente a través de auditorías externas selectivas y en menor medida a través de sumarios ins- 
truidos por el organismo de control a través de algunas de sus divisiones o de contralorías regionales.

El deterioro de la percepción pública o ciudadana sobre la probidad administrativa en Chile a mi juicio no es fruto de la fiscalización llevada a cabo por el organismo contralor, sino en gran medida por la percepción mediática de "casos de corrupción" en la Administración del Estado, que transforman de la mano de los mass media la "opinión publicada" en "opinión pública”.

3. El propio Contralor y otras autoridades han estimado que el proceso de Toma de Razón que efectúa la CGR debe ser revisado en sus bases legales y administrativas: ¿Qué aspectos considera de importancia modificar y/o robustecer?

A.V.: La toma de razón y sus desafíos es un gran tema. El trámite de toma de razón no puede convertirse en un mero examen de legalidad orgánica formal, sino en un examen de juridicidad más completo, que implique el examen del objeto, el fin, motivo, y toda esa materialidad que cubre el fenómeno de la buena administración; entendiendo que ese control no puede abarcar el mérito u oportunidad de la decisión.

El trámite de toma de razón es un control a priori, por esencia, que paraliza momentáneamente la acción administrativa, la aplaza. Dado el volumen de la actividad administrativa, los actos afectos a toma de razón deben ser acotados a las materias fundamentales. Y las demás materias deben ser controladas ex post, pero de manera efectiva y selectiva. Es importante entonces la actual decisión de modificar la resolución de la CGR que regula las materias exentas del trámite de toma de razón. Ojalá se incorporen a esa nueva resolución no solo una taxativa y fría enumeración, sino algunas reglas generales que sirvan para su interpretación.

Hay una distorsión que se ha producido en el último tiempo en medio del trámite de toma de razón en sede contralora, a raíz de las presentaciones de terceros e interesados. Si bien por transparencia debe darse a conocer a todo interesado el texto completo de toda presentación (y no aducir la necesidad de terminar el proceso de toma de razón para liberar la opacidad) y como no puede impedirse que tales interesados realicen presentaciones, acaso es conveniente tener presente las siguientes consideraciones:

i) el antiguo uso o costumbre del órgano contralor de pedir informe al servicio respectivo (una especie de "traslado", en términos procesales), incorpora demoras innecesarias en el proceso. En medio del trámite de toma de razón, toda presentación de tercero si bien debe tenerse presente para la resolución final del órgano contralor, no debiese ser objeto de solicitud de Informe. Por cierto, tales presentaciones deben ser conocidas por el órgano administrativo que requirió la toma de razón, y cabe una espera prudente antes de resolver, por si tal órgano estima necesario hacer alguna presentación. Dada la transparencia que debe presidir el accionar del órgano contralor, este debiera dar a conocer on line tal presentación (y el órgano administrativo diligente debiese estar pendiente de posibles presentaciones de tercero, día a día) o enviarla al órgano administrativo que ha enviado su proyecto de acto administrativo a trámite de toma de razón. Lo anterior, en defensa de la regla y principio de eficiencia administrativa. Pero, la CGR, salvo casos graves, no debiese tener como protocolo la dilación de la toma de razón en función de estas intervenciones de terceros o esperar respuesta de los órganos administrativos respectivos, más allá del tiempo breve en que se debe tomar razón.

ii) en algunas ocasiones las presentaciones de terceros, en medio del trámite de toma de razón, lo han convertido, formalmente, en una sede de decisión contenciosa administrativa, en circunstancias que el órgano contralor carece de competencia jurisdiccional.

Lo anterior provoca la sensación de que la CGR es una instancia o preinstancia cuasi jurisdiccional, respecto de las decisiones posteriores de los Tribunales de justicia. Pues en las habituales estrategias forenses, en la práctica puede originar el siguiente argumento: que la decisión de la CGR puede sindicarse como que ha acogido o denegado la petición de los 
terceros, y así invocarse ante los Tribunales. La sensación que debe dar el accionar de la CGR es de la autonomía más amplia posible, y no solo respecto de los órganos administrativos, sino también respecto de las intervenciones de interesados, que si bien deben ser oídas, no pueden transformarse en un elemento dilatorio de la acción administrativa, mediante el subterfugio de originar procedimientos similares a los "incidentes de previo y especial pronunciamiento" de los procesos judiciales.

En resumen, la CGR, con la más amplia participación de la comunidad interesada y especializada, podría revisar el trámite de Toma de Razón. Siempre es saludable revisar los procesos vigentes, y si lo que se desea es potenciar la eficacia de su procedimiento y que sea un control de juridicidad verdaderamente acotado, ello es adecuado.

Quizás, como proposición, sugiero revisar un uso o costumbre del órgano contralor, de tal manera que él mismo cumpla con el principio y regla de la motivación: esto es, que no solo sea motivado su acto de rechazo de la Toma de Razón; sino que en aquellos casos en que se toma razón, aunque sea brevemente, y con fórmulas que se repitan, pero que sean materialmente coherentes con su decisión, que indiquen los motivos por los cuales el Contralor ha tomado razón. Si la motivación es un principio general que, hoy día, se ha transformado en un estándar para el ciudadano, la CGR debiese ser la primera en dar un paso adelante.

Esto significaría un distanciamiento de una conducta similar en el Poder Judicial: ese extendido y lamentable uso del "vistos: se confirma", propio de los tribunales colegiados.

F.Z.: El control de legalidad de los actos de la Administración del Estado, tanto el trámite de toma de razón como los controles de reemplazos deben ser modificados introduciendo nuevos criterios de "relevancia" para distinguir los actos administrativos afectos y exentos, pero cuidando de extender el control a la Administración invisible sin cobertura legal explícita. Precisamente hoy se está trabajando en el organismo contralor en una resolución sustitutiva de la Res. No 520 de 1996 sobre exención del trámite de toma de razón.
Modificar y actualizar la Res. No 520 se hace imprescindible, ya que como lo ha probado un estudio reciente del administrativista de la Universidad de Chile profesor Luis Cordero V. más del $90 \%$ de los actos sometidos a control preventivo se refieren a movimiento de personal en la Administración.

4. ¿Cómo visualiza usted la relación actual entre la CGR y los tribunales de justicia, particularmente frente a la revisión judicial de actos de los cuales la CGR ha tomado razón?

A.V.: En cuanto a la relación de la Contraloría y los Tribunales, hay una regla y principio fundamental que cabe señalar de partida: los tribunales ejercen, de manera irrenunciable, el control de toda la actuación administrativa, y entre esta la actividad administrativa autónoma, como es la de la Contraloría. Esa autonomía de que goza la CGR de frente a todo órgano de la Administración, no alcanza a ser una excepción a este control judicial. Este control judicial es, por lo demás, una clave de bóveda del Estado de Derecho. Sobre ese supuesto fundamental cabe enmarcar cualquier respuesta de la relación entre la CGR y los Tribunales.

Por otra parte, los tribunales de justicia no pueden excusarse de revisar o controlar los actos administrativos de los que haya tomado razón la CGR. Ello, pues, como se ha dicho, la CGR es un órgano, si bien autónomo del resto de la Administración del Estado, que está sujeto al principio de control judicial. Por lo demás, en este principio se sustenta y se apoya la seguridad jurídica y protección de los particulares de frente a todas las actuaciones administrativas, en sentido amplio.

La toma de razón le imprime al acto administrativo una presunción de legalidad, en cuanto a su ejecutoridad, pero no implica inmunidad jurisdiccional o que el acto o dictamen asociado esté exento de interpretaciones discutibles de la legalidad. Como estas decisiones pueden incidir en los derechos subjetivos públicos de los ciudadanos, siempre puedan ser recurridos por el destinatario del acto ante los tribunales. 
Todo lo cual implica que si los tribunales de justicia conocen de la legalidad o juridicidad de los dictámenes que emita la CGR, están cumpliendo con el principio de sujeción al control de todos los actos de los órganos de la Administración al control judicial.

F.Z.: Este es un campo complejo el de la relación Contraloría General de la República y Poder Judicial, el que ha sido objeto de varias contiendas de competencias, las que se remontan incluso al período preconstitucional trabadas ante la Junta de Gobierno y que versan sobre la justiciabilidad del acto de control expedido en sede de toma de razón y por ende fruto de una competencia constitucional del organismo. En líneas generales concuerdo con las decisiones del Senado de la República recaídas en las contiendas de competencias trabadas, ya que equilibradamente reconocen la fuente constitucional de la competencia de control de legalidad, pero dejan a salvo la justiciabilidad de los actos administrativos de término.

Un caso distinto es el de la justiciabilidad de decisiones de la Contraloría General de la República expedidas a través de su potestad dictaminadora con fuente en su ley orgánica constitucional ficta (Ley No 10.336). En este campo concuerdo parcialmente con los fundamentos de las sentencias de las Cortes de Santiago y Valparaíso dictadas en sede de protección y que dejan sin efecto decisiones del organismo de control, más aún si tratándose de esta potestad dictaminadora, que es un verdadero control de legalidad de segundo nivel, no existe apoyatura de competencia constitucional salvo la referencia residual a la ley orgánica contenida en el artículo 98.

5. Finalmente: ¿qué aspectos considera que deben ser potenciados, hacia el futuro, respecto de la labor que realiza el órgano contralor?

A.V.: El desafío global, no solo de la actuación de la CGR, sino del ordenamiento administrativo, es la buena administración. Es, entonces, un gran tema la relación entre el control de la legalidad y los estándares de cali- dad de la actividad administrativa que espera la ciudadanía.

Entonces, los aspectos que debieran ser potenciados hacia el futuro dicen relación con las formas de controlar y hacer cumplir los estándares de buena administración, los que un sistema jurídico de avanzada debe garantizar e incorporar como objetivos a cumplir, de modo claro y concreto.

Pues, en defensa de los derechos subjetivos públicos, no basta (no debiera bastar) que los particulares solo puedan pedir la anulación de determinados actos administrativos y la responsabilidad derivada, en caso de acciones u omisiones dañosas. Entonces, el logro futuro es diseñar, por vía jurisprudencia o doctrinaria, como un auténtico derecho público subjetivo, el derecho a la buena administración amparada sobre la base de ciertos estándares en la ejecución de la actividad administrativa. Estándares que le permita a los particulares pedir que la Administración actúe eficaz o eficientemente, o que la administración actúe como espera la ciudadanía que lo haga.

Si eso se pudiese controlar, sería un gran avance. En todo caso, esto es distinto al mérito u oportunidad de la actividad administrativa, que es el argumento actual para no entrar en el control de la buena administración. Ese es el desafío.

F.Z.: En una visión prospectiva creo que el proyecto de Reforma Constitucional antes referido sitúa los grandes temas que conciernen a las definiciones estratégicas del organismo contralor: auditoria externa, control de legalidad y justicia de cuentas; aspectos a los que me referiré sucintamente.

La auditoria externa permite a la Contraloría General de la República evaluar los sistemas de control interno de los servicios y entidades fiscalizadas, sometiendo a control la aplicación de normas relativas a administración financiera pública, examinar las operaciones efectuadas y evaluar la exactitud de los estados financieros formulando proposiciones para subsanar o corregir vacíos defectos, a través de los mentados informes de auditoría. Esta auditoría externa de definió en la Ley Or- 
gánica del organismo contralor a través de la Ley No 19.817 de 2002, que admite la duplicidad de auditorías internas y externas e incluso la contratación de auditorías externas por los servicios públicos. Esta auditoría externa no puede evaluar "los aspectos de mérito o conveniencia de las decisiones políticas o administrativas" (artículo $21 \mathrm{~B}$ ); ya que estas cuestiones quedan reservadas a la Administración del Estado y a la decisión política del Gobierno. Precisamente aquí estriba el quid del problema: debe hacerse una diferenciación seria entre Gobierno y Administración por una parte y el control de normas, de aseguramiento del patrimonio público y de la probidad que efectúa Contraloría General de la República, por otra. En suma gobernar y administrar son funciones o tareas distintas a las de controlar, y por ende la competencia del organismo contralor debe ser ejercida con sujeción a legalidad, eficiente y oportunamente para no significar un entrabamiento de la marcha del Estado.

En segundo lugar, el control de legalidad es una función esencial de la Contraloría General de la República y elemento muy importante de un Estado de Derecho y de nuestra tradición republicana. El ámbito del control de legalidad, del control preventivo de toma de razón y de los controles de reemplazo deben seguir siendo definidos por el propio organismo contralor. Sin embargo, estratégicamente me parece que lo gravitante no es definir el objeto del control de legalidad, lo que compete al organismo contralor y a su cabeza jerárquica mediante resoluciones; sino equilibrar el control preventivo y los controles de reemplazo confiriéndole peso o contenido al registro como control de reemplazo. Asimismo se hace necesario en una visión prospectiva abordar la cuestión de los tribunales de lo contencioso administrativo.

Lo que voy a sostener puede sonar a heterodoxia o herejía: un control judicial especializado con procedimientos adecuados ante tribunales de lo contencioso administrativo de los actos de la Administración del Estado, hace innecesario el control de legalidad, en la medida en que este solo confiere una presunción iuris tantum de juridicidad del acto.
Por último, no puede faltar en esta visión prospectiva y estratégica un comentario sobre la justicia de cuentas. Sobre este particular la reforma al Tribunal de Cuentas introducida por la Ley No 19.817 ha significado un enorme avance que aquilata en la jurisprudencia de los últimos años del Tribunal de segunda instancia, tanto en la formalización del procedimiento y estructura de las sentencias como en las garantías de justiciable, dado que en cuanto tribunal ha estado integrado por destacados juristas, no estando de sobra un merecido reconocimiento a los antiguos miembros de este: el ilustre procesalista Hugo Pereira Anabalón y el ilustre constitucionalista Mario Verdugo $\mathrm{M}$.

A mi juicio se hace necesario que el examen de cuentas continúe en el organismo contralor, pero transformando tanto el procedimiento como el tribunal. En cuanto al procedimiento judicial, este debe ser incoado en mérito del examen de cuentas en forma (reparo) o del examen de cuentas ficto (sumario administrativo), judicializando el juzgamiento de cuentas. De esta manera, el sostenimiento de la acción puede corresponder a la División de Auditoria Administrativa del organismo contralor, otorgándole a la Fiscalía intervención como tercero en defensa del interés público, confiriéndole un nuevo rol también al Consejo de Defensa del Estado en la representación procesal del actor. A mi juicio el Tribunal de Cuentas debe salir tanto orgánica como funcionalmente de la Contraloría General de la República para transformarse en un tribunal especial, colegiado y superior de aquellos a que se refiere el inciso final del artículo $5^{\circ}$ del Código Orgánico de Tribunales de integración letrada especializada, independiente e imparcial, sometido, sin perjuicio de los recursos que la ley establezca, a la superintendencia directiva, correccional y económica de la Corte Suprema.

Finalmente, también debemos destacar la necesaria supresión de funciones del organismo contralor prácticamente irrelevantes como la relativa a la contabilidad general de la Nación, materia reservada de hecho a la Dirección de Presupuestos del Ministerio de Hacienda. 